\title{
MicroRNA-146a promotes gastric cancer cell apoptosis by targeting transforming growth factor $\beta$-activated kinase 1
}

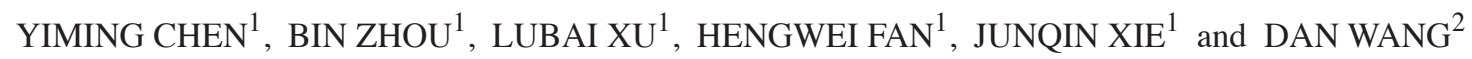 \\ ${ }^{1}$ Department of Hepatobiliary Surgery, The Second Affiliated Hospital and Yuying Children's Hospital of Wenzhou Medical \\ University; ${ }^{2}$ Department of Pediatrics, The First Affiliated Hospital of Wenzhou Medical University, \\ Wenzhou, Zhejiang 325000, P.R. China
}

Received April 17, 2016; Accepted March 17, 2017

DOI: $10.3892 / \mathrm{mmr} .2017 .6640$

\begin{abstract}
Accumulating evidence suggests that microRNA (miR)-146a functions as an oncogene or tumor suppressor in various cancers. However, the role of miR-146a in gastric cancer (GC) remains to be elucidated. The present study investigated the function of miR-146a in GC cells. The results of the present study revealed that miR-146a modulates GC cell apoptosis. Overexpression of miR-146a significantly increased apoptosis of SGC-7901 cells, whereas inhibition of miR-146a protected cells from apoptosis. miR-146a expression in GC cells was inversely correlated with transforming growth factor $\beta$-activated kinase 1 (TAK1) expression, at the mRNA and protein levels. Furthermore, small interfering RNA-mediated silencing of TAK1 enhanced GC cell apoptosis, whereas overexpression of TAK1 promoted survival of GC cells. Overexpression of miR-146a or knockdown of TAK1 led to a marked increase in inhibitor of $\kappa \mathrm{B} \alpha(\mathrm{I} \kappa \mathrm{B} \alpha)$ and a decrease in B-cell lymphoma 2 (Bcl-2) expression levels in SGC-7901 cells. By contrast, silencing of miR-146a or TAK1 overexpression downregulated IкB $\alpha$ and upregulated $\mathrm{Bcl}-2$ expression levels. Therefore, the results of the present study demonstrated a novel negative feedback mechanism to promote $\mathrm{GC}$ cell apoptosis involving the miR-146a/TAK1/nuclear factor- $\kappa \mathrm{B}$ axis.
\end{abstract}

\section{Introduction}

Gastric cancer (GC) is one of the most common human malignant diseases and the second leading cause of cancer-associated mortality worldwide. GC has a particularly high incidence and mortality rate in China $(1,2)$, with 404,565 new cases of GC annually, and 312,432 patients succumbing to disease each

Correspondence to: Dr Dan Wang, Department of Pediatrics, The First Affiliated Hospital of Wenzhou Medical University, 2 Fuxue Road, Wenzhou, Zhejiang 3250000, P.R. China

E-mail:wd2014@126.com

Key words: microRNA-146a, transforming growth factor $\beta$-activated kinase 1 , nuclear factor- $\mathrm{kB}$, apoptosis, gastric cancer year (3). During GC progression, GC cells become increasingly resistant to apoptosis, and therefore refractory to therapy $(4,5)$. Despite improvements in systemic therapy, the prognosis of GC patients remains poor. Therefore, investigating the molecular mechanisms underlying GC progression may be beneficial for the development of novel targeted therapies.

MicroRNAs (miRNAs) are small (19-24 nucleotides in length), noncoding RNAs, that incompletely bind to the $3^{\prime}$ untranslated region of target genes and subsequently negatively regulate expression of multiple genes by inducing translational silencing or degrading the mRNA (4). Accumulating evidence suggests that miRNAs act as oncogenes or tumor suppressors, and that the dysregulation of specific miRNAs is associated with the cancerous transformation of cells (6-8). miRNA $(\mathrm{miR})-146 \mathrm{a}$ is involved in cell proliferation, differentiation and apoptosis (9). miR-146a dysregulation and dysfunction correlates with tumorigenesis and the development of various types of cancer $(10,11)$. However, miR-146a exerts opposite effects in different cancers. It serves as an oncogene in anaplastic thyroid carcinoma and cervical cancer, and as a tumor suppressor in breast and prostate cancers (12-15). Although evidence has suggested that the expression of miR-146a is downregulated in GC, and that downregulation of miR-146a is associated with tumor size and poor prognosis (16), the underlying molecular mechanism of miR-146a and its effects remain largely unclear.

Cancer cells typically acquire a constitutively active nuclear factor (NF)- $\mathrm{kB}$ pathway to promote survival, proliferation and metastatic potential (17). In the majority of cell types, $\mathrm{NF}-\mathrm{\kappa B}$ complexes are retained in the cytoplasm in an inactive form by a family of inhibitory proteins known as inhibitors

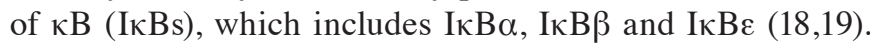
Degradation of IкB facilitates the release and nuclear translocation of NF- $\mathrm{kB}$ (18). Transforming growth factor $\beta$-activated kinase 1 (TAK1), a member of the mitogen-activated protein kinase kinase kinase family, has a prosurvival role in the activation of the NF- $\kappa B$ signaling pathway (20). Loss of TAK1 sensitizes cells for apoptosis or death in the majority of tissue types (21). These results indicate that TAK1 is an important upstream effector of the NF- $\mathrm{KB}$ signaling pathway and that altering the expression of TAK1 may affect apoptosis. In addition, previous studies have demonstrated that miR-146a serves as a negative regulator of constitutive NF- $\mathrm{KB}$ activity in breast 
cancer $(12,17)$. However, whether miR-146a regulates GC cell apoptosis by negatively regulating TAK1 expression remains to be fully elucidated. The present study analyzed the function of miR-146a in GC and demonstrated that it inhibits GC cell apoptosis by targeting TAK1, with subsequent inhibition of the $\mathrm{NF}-\kappa \mathrm{B}$ signaling pathway.

\section{Materials and methods}

Cell culture and transfection. SGC-7901 human GC cells (Shanghai Institute of Cell Biology, Shanghai, China) were cultured in RPMI 1640 medium (Gibco; Thermo Fisher Scientific, Inc., Waltham, MA, USA) containing $10 \%$ fetal bovine serum (Gibco; Thermo Fisher Scientific, Inc.) in a humidified $5 \% \mathrm{CO}_{2}$ incubator at $37^{\circ} \mathrm{C}$. The miR-146a mimic and inhibitor were obtained from Biotend Biological Technology (Shanghai, China). Scrambled negative control mimic or inhibitor (Biotend Biological Technology) were transfected to serve as matched controls. TAK1-Flag plasmid was obtained from Addgene, Inc. (Cambridge, MA, USA). TAK1 siRNA and the scrambled negative control were purchased from Shanghai GenePharma, Co., Ltd. (Shanghai, China). Oligomers used are listed in Table I. Cells (5x10\%/well) were seeded into 6-well plates the day prior to transfection to ensure a suitable cell confluence (70\%) on the day of transfection. Cells were subsequently transfected using Lipofectamine ${ }^{\circledR}$ RNAiMax (Invitrogen; Thermo Fisher Scientific, Inc.) for $48 \mathrm{~h}$ according to the manufacturer's protocol. The miR-146a mimic, inhibitor and respective controls were used at a final concentration of $10 \mathrm{nM}$. siTAK1 and control were used at a final concentration of $20 \mathrm{nM}$. A total of $3 \mu \mathrm{g}$ TAK1-Flag plasmid was used for overexpression of TAK1.

$R N A$ extraction and reverse transcription-quantitative polymerase chain reaction ( $R T-q P C R)$ analysis. Total RNA was extracted from cells using TRIzol ${ }^{\circledR}$ reagent (Invitrogen; Thermo Fisher Scientific, Inc.) according to the manufacturer's protocol. Single-stranded cDNA was synthesized from total RNA using Moloney Murine Leukemia Virus Reverse Transcriptase (Invitrogen; Thermo Fisher Scientific, Inc.) and oligo (dT) 18. qPCR was performed in a 96-well plate on a Bio-Rad CFX Real-Time system using $\mathrm{iQ}^{\mathrm{TM}} \mathrm{SYBR}^{{ }}-$Green Supermix (Bio-Rad Laboratories, Inc., Hercules, CA, USA). For miR-146a detection, the following thermocycling conditions were used: An initial predenaturation step at $50^{\circ} \mathrm{C}$ for $2 \mathrm{~min}$, followed by 40 cycles of denaturation at $95^{\circ} \mathrm{C}$ for $10 \mathrm{~min}$ and annealing at $60^{\circ} \mathrm{C}$ for $1 \mathrm{~min}$. For TAK1, the thermocycling conditions were as follows: An initial predenaturation step at $94^{\circ} \mathrm{C}$ for $5 \mathrm{~min}$, followed by 35 cycles of denaturation at $94^{\circ} \mathrm{C}$ for $30 \mathrm{sec}$, annealing at $60^{\circ} \mathrm{C}$ for $30 \mathrm{sec}$ and extension at $72^{\circ} \mathrm{C}$ for $20 \mathrm{sec}$. Each run was performed in triplicate. The primer sequences used are listed in Table I. The data were expressed as fold change. The comparative quantitation cycle method was used to quantify the expression levels of target genes relative to endogenous controls (22). To normalize the relative abundance of miR-146a and TAK1, U6 and GAPDH served as endogenous controls, respectively (23). For each individual analysis, the control group was used as the calibrator and given a relative value of 1.0. All quantities were expressed as $n$-fold relative to the calibrator.
Table I. Oligomers and primers sequences and used in the present study.

\begin{tabular}{ll} 
Gene (Homo sapiens) & \multicolumn{1}{c}{ Sequence (5'-3') } \\
\hline miR-146a mimic & UGAGAACUGAAUUCCAUGGGUU \\
Mimic NC & UUCUCCGAACGUGUCACGUTT \\
miR-146a inhibitor & AACCCAUGGAAUUCAGUUCUCA \\
Inhibitor NC & ACGUGACACGUUCGGAGAATT \\
siTAK1 & AAAGCGTTTATTGTAGAGCTT \\
siTAK1 NC & ACGUGACACGUUCGGAGAATT \\
miR-146a-forward & CAGTGCGTGTCGTGGAGT \\
miR-146a-reverse & GGGTGAGAACTGAATCCA \\
U6-forward & CTCGCTTCGGCAGCACA \\
U6-reverse & AACGCTTCACGAATTTGCGT \\
TAK1-forward & ATCAGCAGAGTAGCTGCGGT \\
TAK1-reverse & GAGGAGCTTGCTGCAGAGT \\
GAPDH-forward & AGGGCTGCTTTTAACTCTGGT \\
GAPDH -reverse & CCCCACTTGATTTTGGAGGGA
\end{tabular}

miR, microRNA; NC, negative control; TAK1, transforming growth factor $\beta$-activated kinase 1 ; si, small interfering.

Flow cytometry. An Annexin V-Fluorescein Isothiocyanate (FITC)/Propidium Iodide (PI) Staining kit (BD Biosciences, Franklin Lakes, NJ, USA) was used to detect apoptotic cells. Cells were harvested $48 \mathrm{~h}$ following transfection and resuspended in $1 \mathrm{X}$ binding buffer at a concentration of $1 \times 10^{6} \mathrm{cells} / \mathrm{ml}$. Subsequently, cells were stained with $5 \mu 1$ Annexin V-FITC and $5 \mu \mathrm{l} \mathrm{PI}$ for $15 \mathrm{~min}$ at room temperature in the dark. Cells were acquired using a BD Accurri ${ }^{\text {Tit }}$ C6 flow cytometer (BD Biosciences) and data was analyzed using FlowJo software version 7.6.2 (Tree Star, Inc., Ashland, OR USA).

Caspase-3 activity assay. Following transfection with miR-146a mimic or inhibitor, SGC-7901 cells were seeded into 96-well plates at a density of $1 \times 10^{5}$ cells/well, incubated overnight and processed using a Caspase-3 Activity assay kit (Cell Signaling Technology, Inc., Danvers, MA, USA). Cells were lysed in $30 \mu 1 \mathrm{1X}$ PathScan ${ }^{\circledR}$ Sandwich ELISA Lysis Buffer. The cell lysate was mixed with the substrate solution and incubated at $37^{\circ} \mathrm{C}$ in the dark for $2 \mathrm{~h}$, following which the relative fluorescent was measured using a fluorescence plate reader (BioTek Instruments, Inc., Winooski, VT, USA) with an excitation wavelength of $380 \mathrm{~nm}$ and an emission wavelength of $420 \mathrm{~nm}$.

Cell proliferation assay. SGC-7901 cell proliferation was detected using Cell Counting kit-8 (CCK8; Dojindo Molecular Technologies, Inc., Kumamoto, Japan). Following transfection, SGC-7901 cells were seeded into 96-well plates at a density of $4 \times 10^{3}$ cells/well. CCK8 solution $(10 \mu \mathrm{l})$ was added to each well and cells were incubated for $2 \mathrm{~h}$ at $37^{\circ} \mathrm{C}$. Optical density (OD) values were obtained at a wavelength of $450 \mathrm{~nm}$ using a microplate reader (BioTek Instruments, Inc.). The growth curve was constructed using the mean OD value every $24 \mathrm{~h}$ for 3 days. 

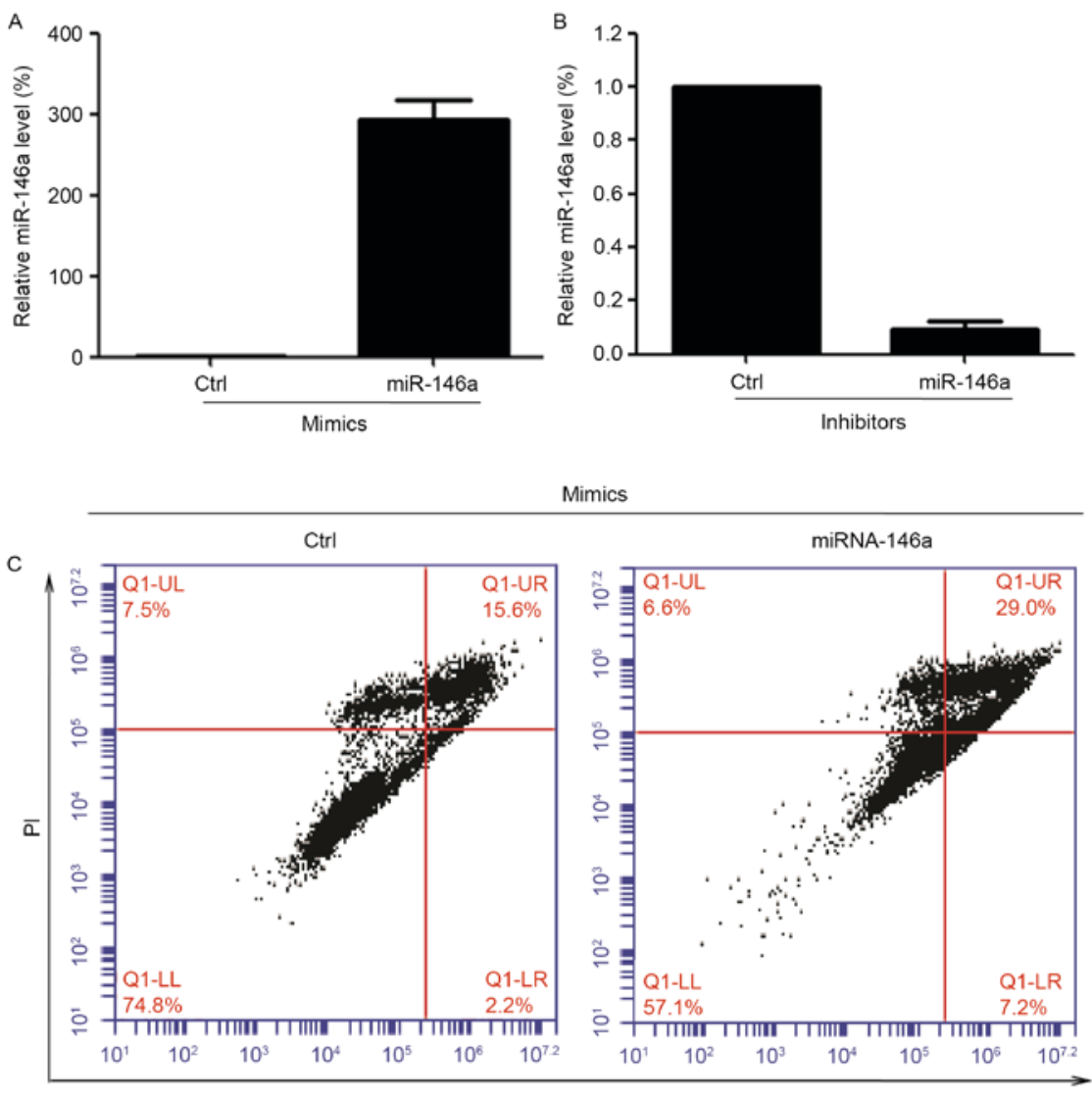

Annexin $\mathrm{V}$

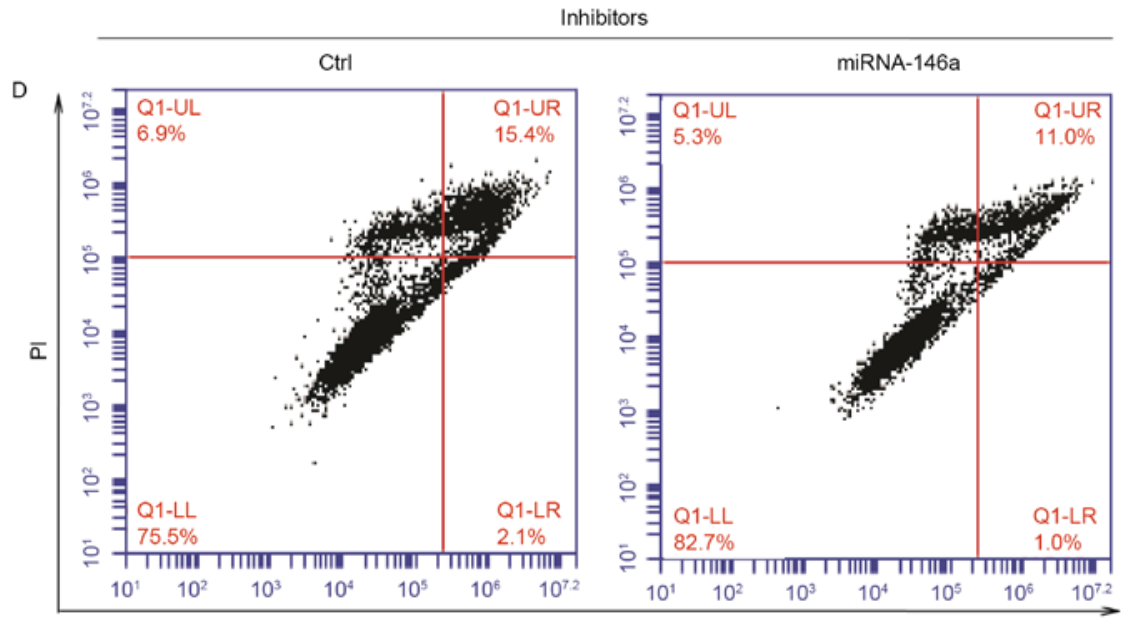

Annexin $\mathrm{V}$
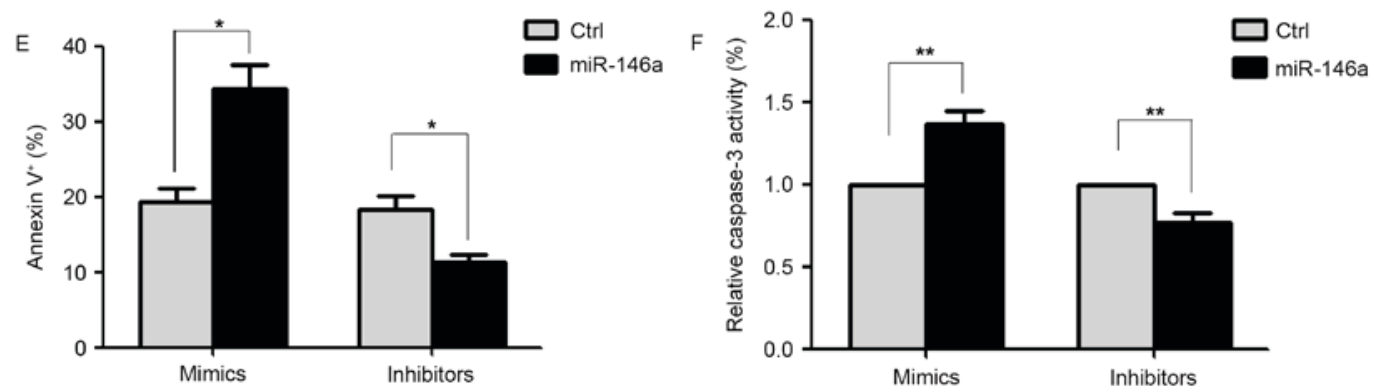

Figure 1. miR-146a regulates SGC-7901 cell apoptosis and proliferation. SGC-7901 cells were transfected with an miR-146a mimic or inhibitor, or scrambled controls, at a final concentration of $10 \mathrm{nM}$ for $48 \mathrm{~h}$. Reverse transcription-quantitative polymerase chain reaction confirmed (A) upregulation of miR-146a levels in mimic-transfected cells and (B) downregulation of miR-146a levels in inhibitor-transfected cells, compared with controls. Apoptosis detection by Annexin V/PI staining followed by flow cytometry in (C) miR-146a overexpressing and (D) miR-146a inhibited cells. (E) The percentage of Annexin $\mathrm{V}^{+}$cells (Annexin $\mathrm{V}^{+} / \mathrm{PI}^{-}$and Annexin $\mathrm{V}^{+} / \mathrm{PI}^{+}$cells). (F) Caspase-3 activity was measured with the Caspase-3 Activity assay kit. Data are expressed as the mean \pm standard deviation of six (E), four (A and B) or two (F) independent experiments. ${ }^{*} \mathrm{P}<0.05$; ${ }^{* *} \mathrm{P}<0.01$. miR, microRNA; PI, propidium iodide; Ctrl, control. 
Western blotting. After $48 \mathrm{~h}$ transfection, cultured SGC-7901 cells were washed with cold PBS once and lysed with lysis buffer $(0.5 \%$ NP40). Equal quantities of protein $(30 \mu \mathrm{g})$ were separated by $10 \%$ SDS-PAGE and transferred to nitrocellulose membranes. Membranes were blocked with 5\% skimmed milk and incubated with the following primary antibodies, diluted 1:1,000, overnight at $4^{\circ} \mathrm{C}$ : Rabbit anti-TAK1 (catalog no. 4505), rabbit anti-IкB $\alpha$ (catalog no. 4812), anti-rabbit B-cell lymphoma 2 (Bcl-2; catalog no. 4223), rabbit anti- $\beta$-actin (catalog no. 4970) and rabbit anti-Flag (catalog no. 14793), all purchased from Cell Signaling Technology, Inc. Blots were washed with TBS containing Tween 20 (TBST) three times for 10 min each time. Subsequently, membranes were incubated with a horseradish peroxidase-conjugated goat anti-rabbit antibody (1:3,000; catalog no. A00098; GenScript, Piscataway, NJ, USA) for $2 \mathrm{~h}$ at room temperature and washed with TBST three times for $10 \mathrm{~min}$ each time. Protein bands were visualized using Enhanced Chemiluminescence Plus (Thermo Fisher Scientific, Inc.) and scanned by Typhoon ${ }^{\text {nt }}$ FLA 9500 (GE Healthcare Life Sciences, Chalfont, UK). Densitometry was quantified using Image $\mathbf{J}$ software (National Institutes of Health, Bethesda, MD, USA) and normalized to $\beta$-actin.

Statistical analysis. Statistical analysis was performed using SPSS software version 19 (IBM SPSS, Armonk, NY, USA). Data are expressed as the mean \pm standard deviation. Paired Student's t-tests or one-way analyses of variance followed by the Bonferroni post hoc test were used to determine statistical significance. $\mathrm{P}<0.05$ was considered to indicate a statistically significant difference.

\section{Results}

miR-146a serves as an apoptotic regulator. Abnormal apoptosis of tumor cells is critical for cancer progression (5). Previous studies have suggested that miR-146a provides negative feedback inhibition of tumor progression $(8,24,25)$. Therefore, the present study evaluated the effect of altering miR-146a expression levels on SGC-7901 cell apoptosis. SGC-7901 cells were transfected with an miR-146a mimic or scrambled control for $48 \mathrm{~h}$. Cells transfected with an miR-146a mimic demonstrated a 300 -fold increase in expression levels of miR-146a compared with control cells, as assessed by RT-qPCR (Fig. 1A). In addition, SGC-7901 cells were transfected with an miR-146a inhibitor or scrambled control for $48 \mathrm{~h}$. Cells transfected with an miR-146a inhibitor exhibited a decrease in miR-146a expression levels to $\sim 10 \%$ of the levels of control cells (Fig. 1B). Apoptosis was assessed in transfected cells using Annexin V/PI staining (Fig. 1C and D). Compared with the scrambled control-transfected cells, overexpression of miR-146a significantly increased the proportion of apoptotic cells $(34.4 \pm 7.9$ vs. $19.4 \pm 4.3 \% ; n=6 ; \mathrm{P}<0.05$; Fig. $1 \mathrm{E})$. The proportion of apoptotic cells following transfection with an miR-146a inhibitor was significantly decreased compared with scrambled control-transfected cells $(11.3 \pm 2.6$ vs. $18.4 \pm 4.1 \%$; $\mathrm{n}=6$; $\mathrm{P}<0.05$; Fig. 1E).

In addition, the effect of miR-146a on apoptosis of SGC-7901 cells was assessed by measuring caspase-3 activity, a feature of apoptosis. Overexpression of miR-146a significantly increased caspase-3 activity, whereas inhibition of miR-146a decreased
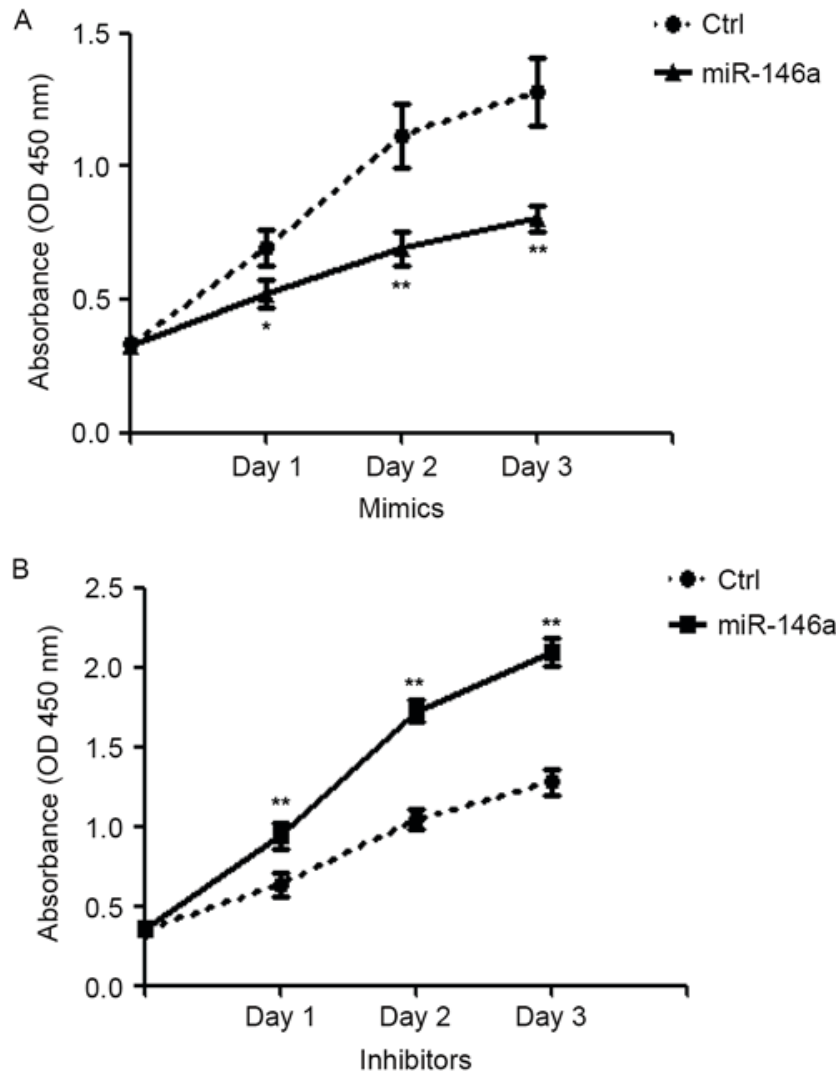

Figure 2. miR-146a expression modulates cell proliferation in gastric cancer cells. SGC-7901 cells were transfected with (A) an miR-146a mimic or (B) an miR-146a inhibitor, or scrambled controls, at a final concentration of $10 \mathrm{nM}$ for $48 \mathrm{~h}$. Proliferation of cells was evaluated using a Cell Counting kit-8 assay. miR-146a overexpression significantly inhibited proliferation of SGC-7901 cells. By contrast, the miR-146a inhibitor significantly promoted the proliferation of SGC-7901 cells compared with the scrambled control. Data are expressed as the mean \pm standard deviation of three independent experiments. ${ }^{*} \mathrm{P}<0.05$ and ${ }^{* *} \mathrm{P}<0.01$ vs. scrambled control at the same time point. miR, microRNA; Ctrl, control; OD, optical density.

caspase-3 activity (Fig. 1F). These results demonstrated that miR-146a may serve a pro-apoptotic role in GC cells.

miR-146a modulates GC cell proliferation. As the rapid proliferation of tumor cells serves a pivotal role in tumor growth and development (5), the present study assessed the effects of altering miR-146a expression levels on the proliferation of SGC-7901 cells using a CCK8 assay. Compared with scrambled control-transfected cells, miR-146a overexpression caused a significant inhibition of cell proliferation (day $1, \mathrm{P}<0.05$; days 2 and 3, P $<0.01$; Fig. 2A). By contrast, knockdown of miR-146a led to a significant increase in cell proliferation compared with the scrambled control $(\mathrm{P}<0.01$; Fig. $2 \mathrm{~B})$. These data suggested that miR-146a expression is inversely correlated with cell proliferation.

TAK1 expression is inversely correlated with miR-146a expression. To determine whether miR-146a regulates TAK1 in GC, the present study assessed the expression of TAK1 following inhibition or overexpression of miR-146a in SGC-7901 cells, using RT-qPCR and western blotting. Compared with scrambled mimic-transfected cells, TAK1 expression at the mRNA (Fig. 3A) and protein (Fig. 3B and C) levels was decreased 
A

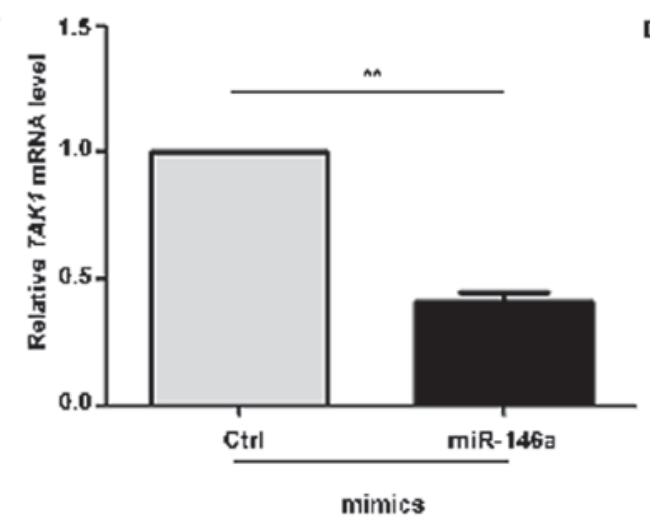

B
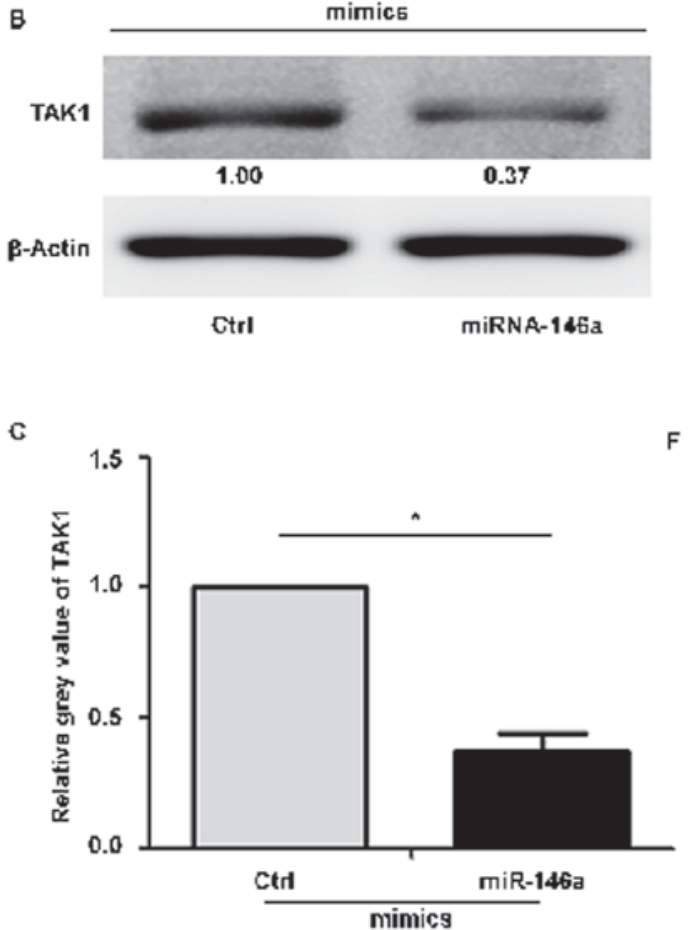

D

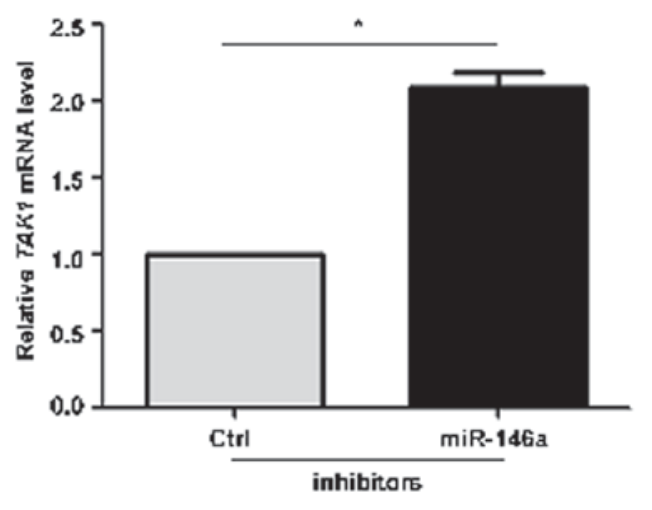

E

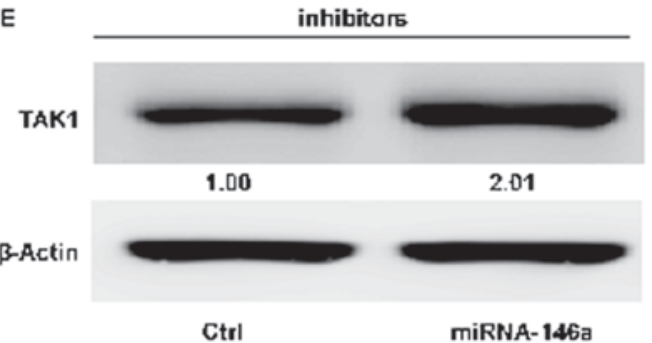

Ctrl

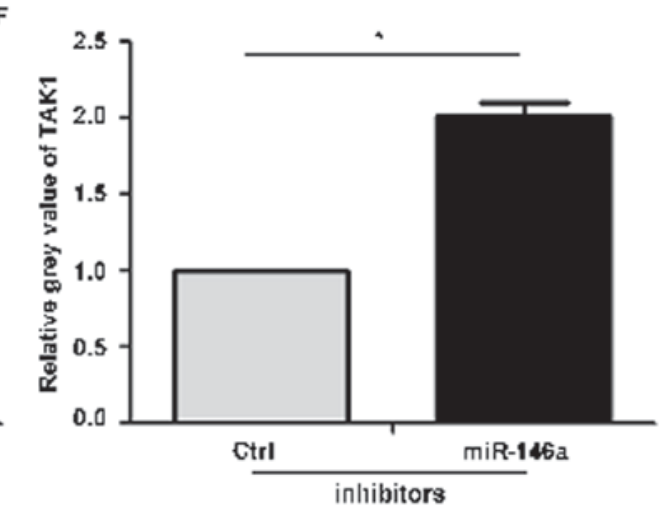

Figure 3. miR-146a expression regulates TAK1 expression levels. SGC-7901 cells were transfected with an miR-146a mimic or inhibitor, or scrambled controls, at a final concentration of $10 \mathrm{nM}$ for $48 \mathrm{~h}$. TAK1 (A) mRNA and (B and C) protein expression levels were analyzed in cells transfected with an miR-146a mimic or scrambled control. TAK1 (D) mRNA and (E and F) protein expression levels were analyzed in cells transfected with an miR-146a inhibitor or scrambled control. Data are expressed as the mean \pm standard deviation and represent six $(\mathrm{A}$ and $\mathrm{D})$ or three $(\mathrm{B}, \mathrm{C}, \mathrm{E}$ and $\mathrm{F})$ independent experiments. $\mathrm{P}<0.05$; ${ }^{* *} \mathrm{P}<0.01$. miR, microRNA; TAK1, transforming growth factor $\beta$-activated kinase 1 ; Ctrl, control.

following transfection with an miR-146a mimic. By contrast, inhibition of miR-146a resulted in significant increases in TAK1 mRNA (Fig. 3D) and protein (Fig. 3E and F) expression levels compared with scrambled controls. These data indicated that miR-146a expression is inversely correlated with TAK1, which may be a potential target molecule of miR-146a in GC cell apoptosis.

Knockdown of TAK1 induces GC cell apoptosis. To investigate whether TAK1 is involved in regulating miR-146a-mediated SGC-7901 apoptosis, the present study knocked down TAKI using siRNA (siTAK1) to determine the effect on GC cell apoptosis. TAK1 mRNA expression levels were significantly decreased following siRNA transfection in SGC-7901 cells compared with scrambled controls (Fig. 4A). Overexpression of TAK1 using a TAK1-Flag plasmid increased protein expression levels of TAK1 compared with control cells (Fig. 4B and C). Apoptosis was assessed in transfected cells using Annexin V/PI staining (Fig. 4D and E). Compared with scrambled control siRNA, the percentage of apoptotic SGC-7901 cells following transfection with siTAK1 was significantly increased (37.33 \pm 8.87 vs. $19.18 \pm 6.30 \%$; $=6 ; \mathrm{P}<0.05$; Fig. $4 \mathrm{~F})$, in accordance with the results obtained with miR-146a overexpression. By contrast, overexpression of TAK1 led to increased SGC-7901 cell survival compared with control cells (Fig. 4G). These data indicated that miRNA-146a mediates apoptosis in human GC via targeting TAKl.

miR-146a induces apoptosis via the $N F-\kappa B$ pathway in $G C$. To confirm that miR-146a-induced GC cell apoptosis involves 

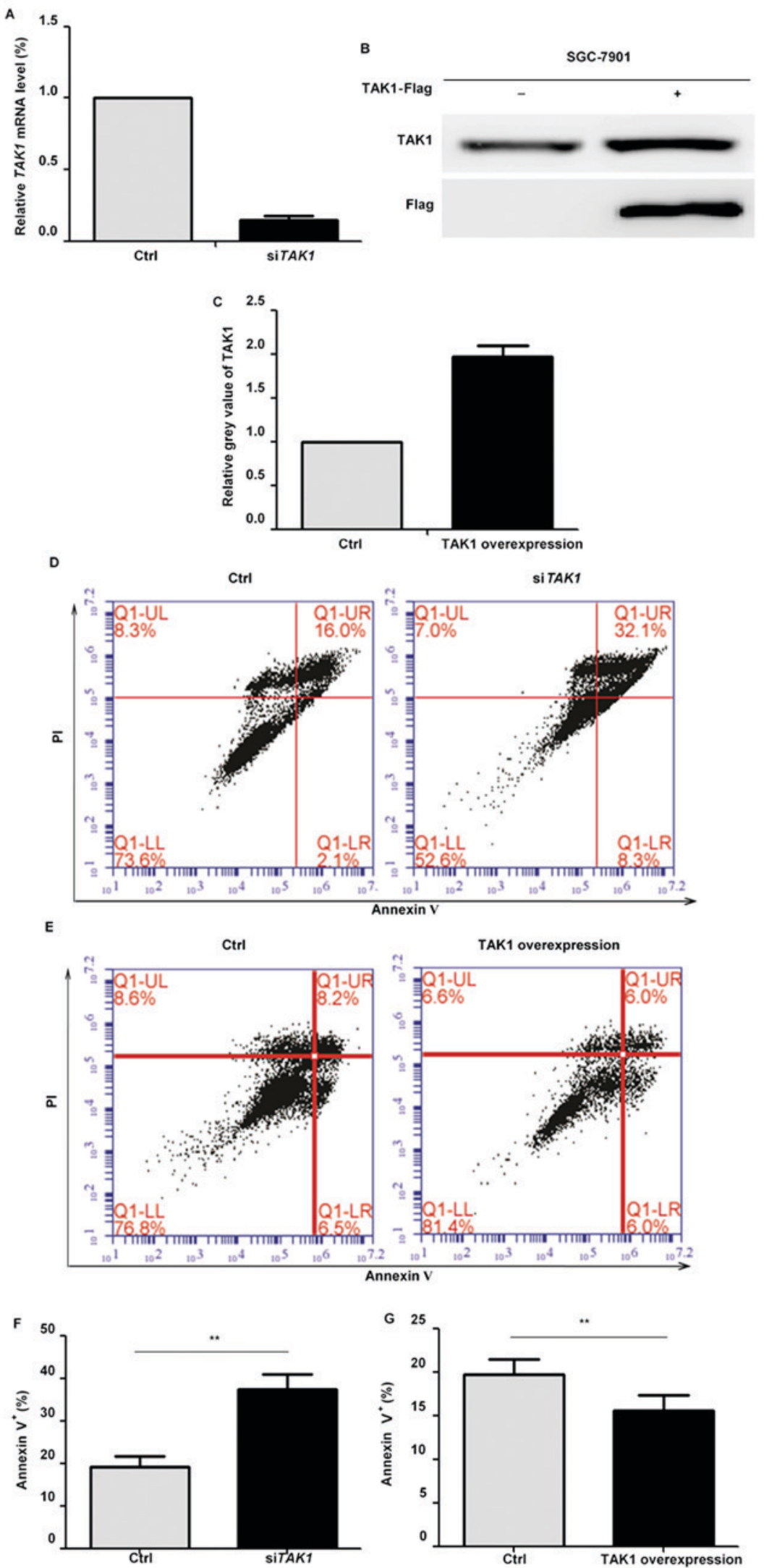

Figure 4. TAK1 regulates gastric cancer cell apoptosis. SGC-7901 cells were transfected with TAK1 siRNA or scrambled control at a final concentration of $20 \mathrm{nM}$, or TAK1-Flag plasmid, for $48 \mathrm{~h}$. (A) Reverse transcription-quantitative polymerase chain reaction confirmed decreased TAK1 mRNA expression levels in siTAK1-transfected cells and (B and C) western blotting confirmed increased TAK1 protein expression levels in TAK1-Flag-transfected cells, compared with controls. Apoptosis detection by Annexin V/PI staining followed by flow cytometry in (D) TAK1 knockdown and (E) TAK1 overexpressing cells. The percentage of Annexin $\mathrm{V}^{+}$cells (Annexin $\mathrm{V}^{+} / \mathrm{PI}^{-}$and Annexin $\mathrm{V}^{+} / \mathrm{PI}^{+}$cells) in (F) TAK1 knockdown and (G) TAK1 overexpressing cells. Data are expressed as the mean \pm standard deviation and represent six independent experiments. ${ }^{*} \mathrm{P}<0.05 ;{ }^{* * *} \mathrm{P}<0.01$. TAK1, transforming growth factor $\beta$-activated kinase 1 ; si, small interfering; PI, propidium iodide; Ctrl, control. 


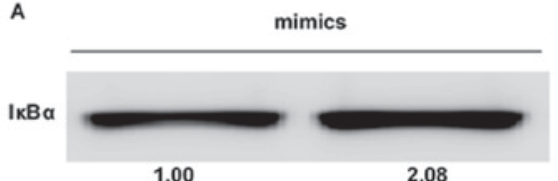

Bcl-2

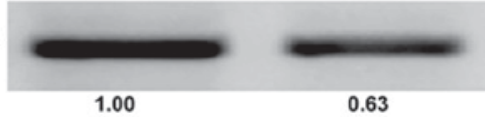

$\beta$-Actin
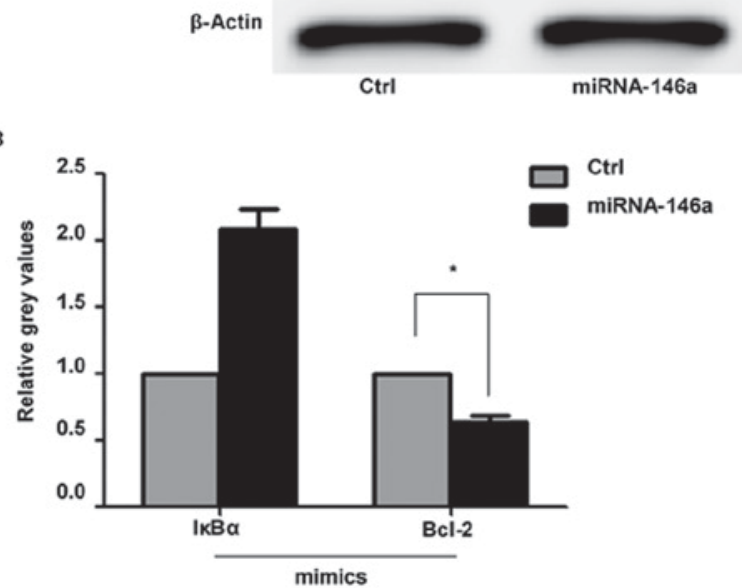

D

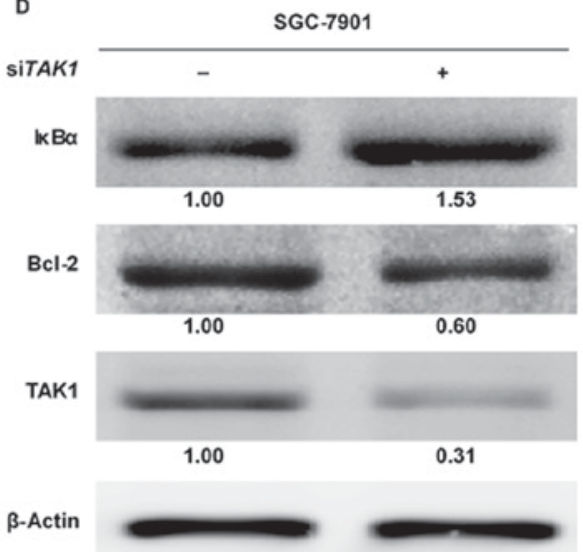

$\beta$-Actin

$\mathbf{F}$
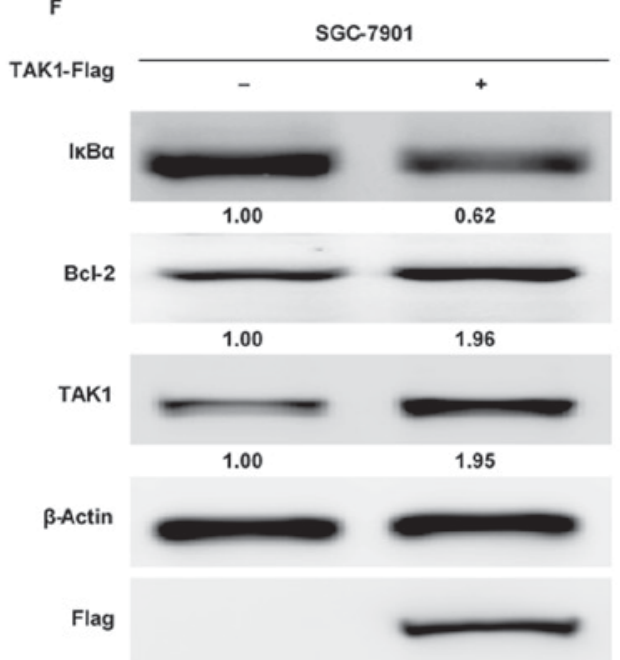

inhibitors

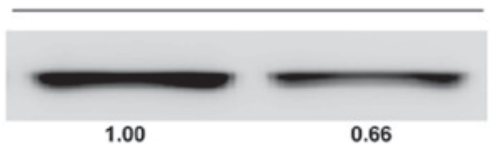

1.00

0.66

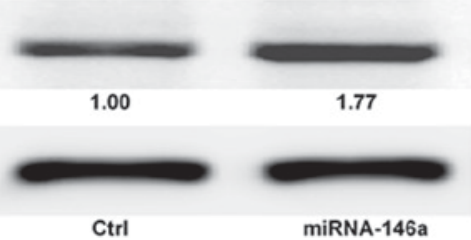

C

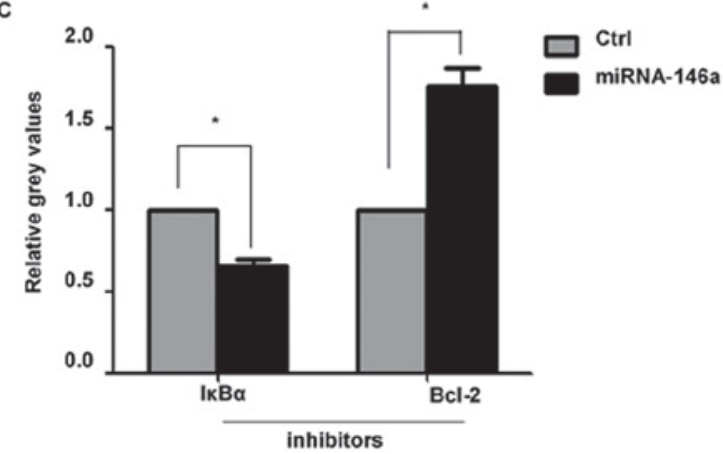

E

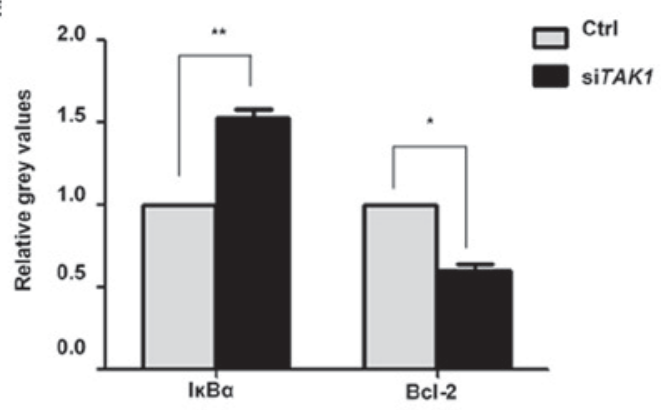

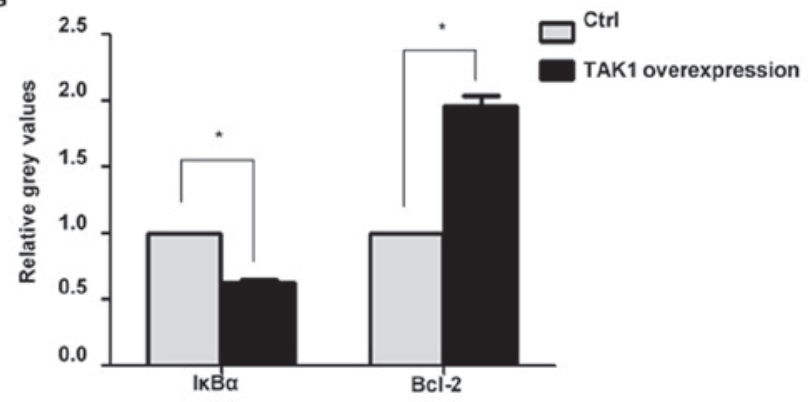

Figure 5. miR-146a modulates apoptosis via the nuclear factor- $\kappa$ B signaling pathway. (A-C) SGC-7901 cells were transfected with an miR-146a mimic or inhibitor, or scrambled controls, at a final concentration of $10 \mathrm{nM}$. TAK1 was (D and E) knocked down or (F and G) overexpressed in SGC-7901 cells. Cells were subsequently analyzed for I $\mathrm{B} \alpha$ and $\mathrm{Bcl}-2$ protein expression levels by western blotting. Blots were quantified by densitometry and normalized to $\beta$-actin. Data are representative of three independent experiments. ${ }^{*} \mathrm{P}<0.05 ;{ }^{* *} \mathrm{P}<0.01$. miR, microRNA; TAK1, transforming growth factor $\beta$-activated kinase 1 ; I $\mathrm{B} \alpha$, inhibitor of $\kappa \mathrm{B} \alpha$; Bcl-2, B-cell lymphoma 2; si, small interfering; Ctrl, control. 
inhibition of the NF- $\mathrm{KB}$ signaling pathway, at least partially via downregulation of the NF- $\kappa \mathrm{B}$ pathway mediator TAK1, the present study detected I $\kappa \mathrm{B} \alpha$ protein expression levels by western blotting. Following transfection with an miR-146a mimic, I $\mathrm{B} \alpha$ protein expression levels were significantly upregulated, whereas these levels were downregulated following transfection of an miR-146a inhibitor (Fig. 5A-C). Knockdown of $T A K 1$ by siRNA additionally led to increased I $\mathrm{I} B \alpha$ protein expression levels (Fig. 5D and E). By contrast, overexpression of TAK1 resulted in decreased expression levels of IкB $\alpha$ (Fig. 5F and G). These results indicated that miR-146a inhibits the NF- $\kappa B$ signaling pathway. The protein expression levels of Bcl-2, a known anti-apoptotic downstream effecter of NF-кB, were also assessed. Transfection with an miR-146a mimic or siTAKl induced a decrease in Bcl-2 expression, whereas transfection of an miR-146a inhibitor led to an increase in Bcl-2 expression in SGC-7901 cells. Increased expression levels of Bcl-2 were additionally observed following overexpression of TAK1. Taken together, these data suggested that miR-146a modulates SGC-7901 cell apoptosis through suppression of the $\mathrm{NF}-\kappa \mathrm{B}$ signaling pathway via targeting TAK1.

\section{Discussion}

The present study revealed three important findings concerning the function of miR-146a in human GC progression. Firstly, miR-146a may be a critical regulator of GC cell proliferation and apoptosis. Overexpression of miR-146a significantly enhanced apoptosis and inhibited proliferation of SGC-7901 cells, whereas inhibition of miR-146a resulted in reduced apoptosis and increased survival. Secondly, miR-146a inversely affected the expression of TAK1 in GC cells. Finally, miR-146a targeted TAK1, leading to inhibition of NF- $\kappa B$ and reduced expression of Bcl-2. Therefore, miR-146a may regulate GC cell apoptosis and proliferation by inhibiting the $\mathrm{NF}-\mathrm{\kappa B}$ signaling pathway via targeting TAK1, suggesting a novel negative feedback mechanism for miR-146a in the regulation of GC development.

The capacity of tumor cell populations to expand in number is attributed to the rate of cell growth and apoptosis. Rapid proliferation and evasion of apoptosis, two of the primary features of cancer cells, are the leading causes of GC progression $(5,26)$. Hou et al $(25)$ revealed that miR-146a enhances apoptosis and inhibits survival in MKN-45 cells, a poorly differentiated GC cell line. Consistent with these results, the present study demonstrated that overexpression of miR-146a promoted apoptosis and inhibited proliferation in SGC-7901 cells, a moderately differentiated GC cell line, whereas inhibition of miR-146a decreased apoptosis and increased proliferation. These data suggested that miR-146a is an important regulator of GC cell survival. Previously, up- and down-regulated expression of miR-146a has been reported in GC tissues $(16,25,27)$. miR-146a expression was revealed to be high in noncancerous prostatic epithelium and gradually decreased with cancer progression (28). Reduced levels of miR-146a have been associated with lymph node metastasis and venous invasion (16). Furthermore, the loss of miR-146a may be a late event in the progression of GC (10). Therefore, the conflicting data regarding the expression of miR-146a may be attributed to different tumor progression status and clinical stages. of GC. Although the expression of miR-146a in GC remains controversial, there is a consensus that miR-146a acts as a tumor suppressor in GC progression by inhibiting proliferation and promoting apoptosis.

In GC, the NF- $\mathrm{kB}$ signaling pathway serves a pivotal role in modulating cell survival, apoptosis, immunity and inflammation, and NF- $\mathrm{\kappa B}$ activation is associated with poor prognosis $(27,29)$. Various regulatory proteins, including $\mathrm{I} \kappa \mathrm{B} \alpha$ and $\mathrm{Bcl}-2$, are direct transcriptional targets of $\mathrm{NF}-\kappa \mathrm{B}$, thus forming a negative feedback loop (30). Recently, evidence has demonstrated that phosphorylation of I $\mathrm{I} B \alpha$ at Ser-32 is necessary for its degradation, and that this phosphorylation is decreased by overexpression of miR-146a in breast cancer cells (12). In addition, upregulation of $\mathrm{I} \kappa \mathrm{B} \alpha$ by overexpression of miR-146a has been revealed in non-small cell lung cancer cells (31). Consistent with this, the present study demonstrated that overexpression of miR-146a increased I $\mathrm{B} \alpha$ expression and decreased Bcl-2 expression in SGC-7901 cells. By contrast, inhibition of miR-146a downregulated expression levels of I $\mathrm{B} \alpha$ and upregulated those of $\mathrm{Bcl}-2$. Therefore, the results of the present study supported published data suggesting that miR-146a modulates SGC-7901 apoptosis by inhibition of the NF- $\kappa B$ signaling pathway.

TAK1, a key molecular component in the determination of cell fate, is an upstream kinase of NF- $\mathrm{B}(20,21)$. Accumulating evidence suggests the existence of a TAK1-NF- $\kappa \mathrm{B}$ loop in various diseases $(21,30)$. The present study identified the mechanism underlying miR-146a regulation of GC cell apoptosis through the miR-146a/TAK1/NF- $\mathrm{KB}$ axis. Expression of TAK1 was inversely modulated by miR-146a. Furthermore, overexpression of miR-146a or silencing of TAK1 led to increased expression levels of IкB $\alpha$ in SGC-7901 cells. By contrast, inhibition of miR-146a or overexpression of TAK1 decreased the protein expression levels of IкB $\alpha$. Previous studies have suggested that TAK1 may phosphorylate the I $\mathrm{KB}$ kinase complex for degradation and release NF- $\kappa \mathrm{B}(20,32)$, which may subsequently translocate to the nucleus and activate a range of genes involved in inhibition of apoptosis and promotion of proliferation $(20,21)$. Therefore, miR-146a may act as an NF- $\kappa \mathrm{B}$ signaling pathway negative regulator via repression of TAK1 in GC cells.

In conclusion, the results of the present study suggested that miR-146a, serving as a tumor suppressor, may significantly promote GC cell apoptosis by inhibition of the NF- $\mathrm{KB}$ signaling pathway via targeting TAK1. The newly identified miR-146a/TAK1/NF- $\mathrm{BB}$ axis provides a novel insight into GC progression. These findings suggested that miR-146a may be a potential therapeutic target for the treatment of GC.

\section{Acknowledgements}

The present study was supported by the Social Programs of Wenzhou Technology Bureau (grant no. Y20130231).

\section{References}

1. Torre LA, Bray F, Siegel RL, Ferlay J, Lortet-Tieulent J and Jemal A: Global cancer statistics, 2012. CA Cancer J Clin 65: $87-108,2015$.

2. Chen W, Zheng R, Baade PD, Zhang S, Zeng H, Bray F, Jemal A Yu XQ and He J: Cancer statistics in China, 2015. CA Cancer J Clin 66: 115-132, 2016. 
3. Chen W, Zheng R, Zhang S, Zhao P, Zeng H, Zou X and He J: Annual report on status of cancer in China, 2010. Chin J Cancer Res 26: 48-58, 2014.

4. Schickel R, Park SM, Murmann AE and Peter ME: miR-200c regulates induction of apoptosis through CD95 by targeting FAP-1. Mol Cell 38: 908-915, 2010.

5. Hanahan D and Weinberg RA: The hallmarks of cancer. Cell 100: 57-70, 2000.

6. Yanaka Y, Muramatsu T, Uetake H, Kozaki K and Inazawa J: miR-544a induces epithelial-mesenchymal transition through the activation of WNT signaling pathway in gastric cancer. Carcinogenesis 36: 1363-1371, 2015.

7. Liu X, Ge X, Zhang Z, Zhang X, Chang J, Wu Z, Tang W, Gan L, Sun M and Li J: MicroRNA-940 promotes tumor cell invasion and metastasis by downregulating ZNF24 in gastric cancer. Oncotarget 6: 25418-25428, 2015.

8. Yao Q, Cao Z, Tu C,Zhao Y, Liu H and Zhang S: MicroRNA-146a acts as a metastasis suppressor in gastric cancer by targeting WASF2. Cancer Lett 335: 219-224, 2013.

9. Park H, Huang X, Lu C, Cairo MS and Zhou X: MicroRNA-146a and microRNA-146b regulate human dendritic cell apoptosis and cytokine production by targeting TRAF6 and IRAK1 proteins. J Biol Chem 290: 2831-2841, 2015.

10. Hou Z, Yin H, Chen C, Dai X, Li X, Liu B and Fang X microRNA-146a targets the L1 cell adhesion molecule and suppresses the metastatic potential of gastric cancer. Mol Med Rep 6: 501-506, 2012.

11. Garcia AI,Buisson M,Bertrand P,Rimokh R, Rouleau E,LopezBS, Lidereau R, Mikaélian I and Mazoyer S: Down-regulation of BRCA1 expression by miR-146a and miR-146b-5p in triple negative sporadic breast cancers. EMBO Mol Med 3: 279-290, 2011.

12. Liu R, Liu C, Chen D, Yang WH, Liu X, Liu CG, Dugas CM, Tang F, Zheng P, Liu Y and Wang L: FOXP3 controls an miR-146/NF- $\mathrm{BB}$ negative feedback loop that inhibits apoptosis in breast cancer cells. Cancer Res 75: 1703-1713, 2015.

13. Stuckrath I, Rack B, Janni W, Jäger B, Pantel K and Schwarzenbach H: Aberrant plasma levels of circulating miR-16, miR-107, miR-130a and miR-146a are associated with lymph node metastasis and receptor status of breast cancer patients. Oncotarget 6: 13387-13401, 2015.

14. Wang X, Tang S, Le SY, Lu R, Rader JS, Meyers C and Zheng ZM: Aberrant expression of oncogenic and tumor-suppressive microRNAs in cervical cancer is required for cancer cell growth. PLoS One 3: e2557, 2008

15. Pacifico F, Crescenzi E, Mellone S, Iannetti A, Porrino N, Liguoro D, Moscato F, Grieco M, Formisano S and Leonardi A: Nuclear factor- $\{$ kappa $\}$ B contributes to anaplastic thyroid carcinomas through up-regulation of miR-146a. J Clin Endocrinol Metab 95: 1421-1430, 2010.

16. Kogo R, Mimori K, Tanaka F, Komune S and Mori M: Clinical significance of miR-146a in gastric cancer cases. Clin Cancer Res 17: 4277-4284, 2011.

17. Bhaumik D, Scott GK, Schokrpur S, Patil CK, Campisi J and Benz CC: Expression of microRNA-146 suppresses NF-kappaB activity with reduction of metastatic potential in breast cancer cells. Oncogene 27: 5643-5647, 2008.
18. Perkins ND: Integrating cell-signalling pathways with NF-kappaB and IKK function. Nat Rev Mol Cell Biol 8: 49-62, 2007.

19. Espinosa L, Margalef $P$ and Bigas A: Non-conventional functions for NF-kappaB members: The dark side of NF- $\kappa$ B. Oncogene 34: 2279-2287, 2015

20. Singh A, Sweeney MF, Yu M, Burger A, Greninger P, Benes C, Haber DA and Settleman J: TAK1 inhibition promotes apoptosis in KRAS-dependent colon cancers. Cell 148: 639-650, 2012.

21. Mihaly SR, Ninomiya-Tsuji J and Morioka S: TAK1 control of cell death. Cell Death Differ 21: 1667-1676, 2014.

22. Livak KJ and Schmittgen TD: Analysis of relative gene expression data using real-time quantitative PCR and the 2(-Delta Delta C(T)) Method. Methods 25: 402-408, 2001

23. Li Y, Zhao L, Shi B, Ma S, Xu Z, Ge Y, Liu Y, Zheng D and Shi J: Functions of miR-146a and miR-222 in Tumor-associated macrophages in breast cancer. Sci Rep 5: 18648, 2015.

24. Sun Q, Zhao X, Liu X, Wang Y, Huang J, Jiang B, Chen Q and Yu J: miR-146a functions as a tumor suppressor in prostate cancer by targeting Rac1. Prostate 74: 1613-1621, 2014.

25. Hou Z, Xie L, Yu L, Qian X and Liu B: MicroRNA-146a is down-regulated in gastric cancer and regulates cell proliferation and apoptosis. Med Oncol 29: 886-892, 2012.

26. Hanahan D and Weinberg RA: Hallmarks of cancer: The next generation. Cell 144: 646-674, 2011

27. Crone SG, Jacobsen A, Federspiel B, Bardram L, Krogh A, Lund AH and Friis-Hansen L: microRNA-146a inhibits G protein-coupled receptor-mediated activation of NF- $\kappa \mathrm{B}$ by targeting CARD10 and COPS8 in gastric cancer. Mol Cancer 11: 71,2012 .

28. Avci CB, Harman E, Dodurga Y, Susluer SY and Gunduz C: Therapeutic potential of an anti-diabetic drug, metformin: Alteration of miRNA expression in prostate cancer cells. Asian Pac J Cancer Prev 14: 765-768, 2013.

29. Ma H, Gao L, Li S, Qin J, Chen L, Liu X, Xu P, Wang F, Xiao H, Zhou S, et al: CCR7 enhances TGF-B1-induced epithelial-mesenchymal transition and is associated with lymph node metastasis and poor overall survival in gastric cancer. Oncotarget 6: 24348-24360, 2015.

30. Oeckinghaus A, Hayden MS and Ghosh S: Crosstalk in NF-кB signaling pathways. Nat Immunol 12: 695-708, 2011.

31. Chen G, Umelo IA, Lv S, Teugels E, Fostier K, Kronenberger P, Dewaele A, Sadones J, Geers C and De Greve J: miR-146a inhibits cell growth, cell migration and induces apoptosis in non-small cell lung cancer cells. PLoS One 8: e60317, 2013.

32. Hou DX, Luo D, Tanigawa S, Hashimoto F, Uto T, Masuzaki S, Fujii M and Sakata Y: Prodelphinidin B-4 3'-O-gallate, a tea polyphenol, is involved in the inhibition of COX-2 and iNOS via the downregulation of TAK1-NF-kappaB pathway. Biochem Pharmacol 74: 742-751, 2007. 